\title{
MASTITE SUBCLÍNICA BOVINA: TEORES DE PROTEÍNA NO LEITE APÓS O TRATAMENTO DURANTE A LACTAÇÃO
}

\section{L.F. Zafalon', A. Nader Filho², M.R.B. de Carvalho², T.M.A. de Lima²}

${ }^{1}$ EMBRAPA, Centro de Pesquisa de Pecuária do Sudeste, Rod. Washington Luiz, km 234, CEP 13560-970, São Carlos, SP, Brasil. E-mail: zafalon@cppse.embrapa.br

\section{RESUMO}

Verificou-se os teores protéicos do leite em 135 quartos mamários com mastite subclínica causada por Staphylococcus aureus divididos em dois grupos, tratados (67) e não tratados (68). Utilizou-se para a tratamento a dose de $150 \mathrm{mg}$ de gentamicina, uma vez ao dia e por três dias consecutivos, em uma propriedade com rebanho leiteiro experimental localizada na região de Barretos, interior do Estado de São Paulo. Foram considerados curados os quartos mamários cujas amostras de leite mostraram-se negativas ao isolamento das cepas de S. aureus 30 dias após o tratamento. Determinou-se as frações de proteína total (PT), proteína verdadeira (PV), caseína (CAS) e soroproteínas (SP), antes e depois do tratamento durante a lactação. As análises do extrato seco total (EST), da contagem de células somáticas (CCS) e da produção de leite também foram efetuadas. Após as análises dos dados, verificou-se que não houve diferença significativa para PT, PV eSP após o tratamento, enquanto a mesma diferença encontrada em quartos mamários doentes para CAS, antes e após o tratamento, também foi verificada para os quartos sadios que serviram de controle. Dessa maneira, concluiu-se que o tratamento da mastite subclínica causada por $S$. aureus durante a lactação não acarretou melhoria na qualidade do produto quando os itens analisados foram os teores protéicos do leite.

PALAVRAS-CHAVE: Leite, antibiótico, proteínas, mastite.

\section{ABSTRACT}

BOVINESUBCLINICALMASTITIS:MILK-PROTEINFRACTIONAFTERTREATMENTDURING LACTATION. The present study assessed the protein fractions of the milk in 135 mammary quarters with subclinical mastitis caused by Staphylococcus aureus. These quarters were classified in two groups: treated (67) and not treated (68). The antimicrobial drug used for the treatment was gentamicin $(150 \mathrm{mg}$ ) once a day and for three consecutive days. The herd was situated in the Barretos region, state of São Paulo, Brazil. Mammary quarters were considered cured when samples of milk were negative for the isolation of $S$. aureus 30 days after the treatment. Fractions of total protein, true protein, casein and whey protein were determined, before and after lactation. Total solids, somatic cell counts and milk production were also analyzed. After the analyses of the data, it was verified that there was no significant difference for total protein, true protein or whey protein after the treatment, while the same difference found in sick mammary quarters for casein, before and after the treatment, was verified for the healthy quarters. In conclusion, the treatment of subclinical mastitis caused by $S$. aureus during lactation did not produce improvement in the quality of the product when the milk protein levels were analyzed.

KEY WORDS: Milk, antibiotic, protein, mastitis.

\section{INTRODUÇÃO}

Staphylococcus aureus é reconhecido como o patógeno mais frequentemente isolado em casos de mastite subclínica bovina, relacionado entreos microorganismos mais contagiosos e, por este motivo, é grande a importância de cuidados que previnam a sua disseminação no rebanho durante a ordenha (FERREIRA et al., 2006).

Estudos que investigam o tratamento de vacas com alta contagem de células somáticas durante a lactação podem produzir resultados variados, ao indicarem a efetividade em reduzir o número de células somáticas do leite ou que o tratamento durante a

\footnotetext{
${ }^{2}$ Universidade Estadual Paulista, Faculdade de Ciências Agrárias e Veterinárias, Jaboticabal, SP, Brasil.
} 
lactação não é eficaz nem promotor de resultados positivos financeiramente (SHEPHARD et al., 2000).

FONSECA; SANTOS (2000) relataram que, entre os componentes do leite, as proteínas são as que apresentam a maior variaçãoem animais com mastite. Estes autores concordam que pode haver decréscimo significativo nos teores de caseína total e elevação das proteínas do soro, incluindo grande elevação nas imunoglobulinas, apesar da possibilidade da variação da porcentagem de proteína total do leite não ser significativa.

Um tema debatido no Brasil é o pagamento diferenciado do leite baseadoem critérios de qualidade da matéria-prima fornecida aos laticínios. SegundoFonSECA (2001), trata-se de uma evolução do sistema de comercialização do leite e de um aprimoramento das relações entreindústria e produtores, além de premiar com uma bonificação os produtores que dedicaram esforço, empenho e recursos financeiros para produzir uma matéria-prima de qualidade superior. Dentre os critérios que podem ser utilizados para efeito de pagamento diferenciado são destacadas a composição do produto, a sua qualidade higiênica e parâmetros físico-químicos. Oconteúdo decaseína, por exemplo, tem papel importante na produção de queijos, o que justifica a relevância do seu acompanhamento, concomitante com outras frações protéicas.

Uma vez que os teores de sólidos totais podem contribuir com o pagamento do leite por qualidade e os teores de proteína do leite estão entre os constituintes sólidos do produto, procurou-se verificar os efeitos do tratamento antimicrobiano da mastite subclínica por $S$. aureus durante a lactação sobre alguns teores protéicos do leite e compará-los antes e após a realização da terapia.

\section{MATERIAL E MÉTODOS}

Os animais (40 vacas lactantes) faziam parte de um rebanho pertencente à propriedade rural produtora de leite tipo "C" situada no Município de Colina, região de Barretos, Estado de São Paulo, cuja produção de leite era de, aproximadamente, $400 \mathrm{~L}$ diários. Na referida propriedade a ordenha era mecânica, realizada uma vez ao dia, sendo utilizado o sistema de "latão ao pé". A população bovina era constituída por animais da raça Holandesa 7/8, cuja alimentação baseava-se em concentrado (rolão de milho, milho, calcário, fosfato bicálcico, uréia e sulfato de amônia) e pastagens dePanicummaximum cultivar Tanzânia. No período das secas foi realizada suplementação com silagem de milho e a quantidade de concentrado era aumentada de $1 \mathrm{~kg} /$ cabeça/dia para $2 \mathrm{~kg} /$ cabeça/dia. Além disso, os animais recebiam suplementação mineral "à vontade" (fórmula comercial).
Durante o período compreendido entre maio de 2000 e maio de 2002, todas as vacas lactantes aparentemente sadias foram submetidas às provas do "California Mastitis Test" (CMT) para o diagnóstico da mastite subclínica. Para a efetivação das análises protéicas, de extrato seco total (EST), da contagem de células somáticas (CCS) e de produção láctea foram selecionadas as fêmeas que apresentavam pares de quartos mamários cujo leite mostrava-se reagente ao CMT em um de seus quartos e não reagente no quarto oposto correspondente.

A confirmação de S. aureus como responsável pela etiologia infecciosa da mastite subclínica foi realizada após a colheita de duas amostras de leite contendo de 5 a $10 \mathrm{~mL}$, obtidas no início da ordenha e originadas de um mesmo quarto mamário. Estas amostras foram semeadas $(10 \mu \mathrm{L})$ sobre a superfície de ágar sangue de ovino contido em placas de Petri. A identificação baseou-se nas características decrescimento e realização de esfregaços corados pelo método de Gram. As colônias classificadas como cocos Grampositivos foram submetidas às provas da catalase e da coagulase lenta com plasma de coelho (HolmberG, 1973). As cepas catalase e coagulase positivas foram submetidas à prova para verificação da produção de acetoína e as amostras acetoína-positivas foram testadas quanto à utilização ou não da maltose e da trealose. As amostras que se mostraram positivas a estas duas últimas provas foram classificadas como S. aureus (Holt et al., 1994). Os quartos mamários não reagentes ao CMT foram confirmados como sadios após a ausência de crescimento de micro-organismos a partir das amostras de leite.

O tratamento foi realizado em 67 quartos mamários após o término da ordenha, durante três dias consecutivos, sendo utilizada a dose de $150 \mathrm{mg}$ de gentamicina (Gentocin $^{\circledR}$ - Schering-Plough), por infusão intramamária, uma vez ao dia. Todas as cepas de $S$. aureus isoladas a partir dos quartos mamários apresentaram sensibilidadeao princípioativo contido no medicamento nos testes "in vitro", antes do tratamento. A realização deste foi feita após a ordenha dos quartos mamários da maneira mais completa possível e posteriorhigienização comalgodãoembebidoemálcool $70 \%$. Realizou-se a inserção parcial da cânula da bisnaga contendo o medicamento e, após a sua infusão, efetuouse a massagem dos úberes para melhor distribuição do produto. Oacompanhamento da evolução dos casos de mastite subclínica que não foram tratados foi realizado em outros 68 quartos mamários.

Os quartos foram considerados curados quando as amostras deleitemostraram-senegativasaoisolamento de S.aureusemexames realizados30 diasapósotérmino dos tratamentos. Os quartos mamários sem tratamento foramconsideradoscuradosdeformaespontâneaquando, em um intervalo de 30 dias entre as colheitas das 
amostras de leite, deixaram de apresentar o isolamento de S.aureus. Ainterpretação dos resultados bacteriológicos seguiu o preconizado por HARMON et al. (1990).

O método de referência para a determinação da CCS foi a contagem direta de esfregaços de leite corados com o corante Broadhurst-Paley, em microscópio óptico em objetiva de imersão(IDF,1991). As amostras de leite obtidas para as análises de EST, proteínas e CCS foram oriundas da produção total dos quartos mamários. A pesagem do leite foi feita com a utilização de um dispositivo acoplado aos copos da ordenhadeira mecânica, o que permitia a obtenção individualizada do leite oriundo de cada quarto mamário. Utilizou-se neste processo latões com capacidade para $5 \mathrm{~L}$ de leite, sendo que o conteúdo era transvasado para um recipiente plástico que foi submetido à pesagem em balança de precisão. As pesagens foram efetuadas durante dois dias consecutivos (BAILEy et al.,1998). Após a verificação da produção de leite originada de cada quarto mamário, calculava-se a produção média nos dois dias de pesagens.

As análises de EST do leite foram efetuadas após a aferição dos teores de gordura por aparelho eletrônico (Milko-Tester ${ }^{\circledR}$, modelo mk 3.2 - ITR), calibrado pelo método convencional de Gerber (ZAFALON, 2003) e a aferição da densidade relativa do leite (ZAFALON et al., 2005). O EST foi determinado pela utilização do Calculador de Ackermann (Gerber Instruments).

Procedeu-se as determinações de proteína total (PT), proteína verdadeira(PV), caseínas (CAS) esoroproteínas (SP) doleitedeacordocomométodo deKjeldhal (micro), preconizado por metodologia padronizada pela INTERNATIONAL DAIRY FEDERATION (1962). Os valores foram submetidosàanálise devariânciaouaotestedeKruskalWallis, de acordo com os desvios-padrão encontrados, complementados pelos testes de Tukey-Kramer e de Dunn e as taxas de cura foram comparadas utilizandose o teste exato de Fisher (SAMPAIO, 1998).

\section{RESULTADOS E DISCUSSÃO}

As taxas de cura foram de $82,1 \%$ e $7,4 \%$ para os grupos com tratamento e sem tratamento, respectiva- mente (Tabela 1). CostA et al. (1997) efetuaram o tratamento de vacas com mastite subclínica com cefacetril, gentamicina e cloxacilina e obtiveram a cura microbiológica e/ou resultados traços ou negativos ao CMT de, respectivamente, 78,6\%, 86,1\% e 95,4\% dos quartos tratados. Os estafilococos corresponderam a $33,6 \%$ dos agentes isolados antes do tratamento. LANGONI et al. (1997) obtiveram taxas de cura para mastite subclínica causada por Staphylococcus aureuse Streptococcus agalactiae que variaram de $85,3 \%$ a 90,3\% em tratamentos realizados uma e duas vezes ao dia, ao utilizarem hidroiodeto de penetamato associado com a dihidroestreptomicina, sulfato de framicetina e prednisolona. Oliver et al. (2004) verificaram taxa de cura de $36 \%$ com a utilização de ceftiofur contra $S$. aureus, inferior às encontradas pelos mesmos autores para outros microrganismos também isolados.

Fatores conjuntos precisam ser analisados após o tratamento da mastite subclínica durante a lactação, como a conduta terapêutica, a idade e o número de lactações do animal, a duração do tratamento e o tipo de micro-organismo responsável pela doença. $\mathrm{O} S$. aureus, por exemplo, pode permanecer encapsulado no interior de células de defesa da glândula mamária, o que compromete a eficácia da terapia antimicrobiana (Deluyker et al., 2005). A presença de animais mais jovens, a aplicação do antimicrobiano pelo período recomendado pelo fabricante e os cuidados com os procedimentos higiênicos durante as aplicações dos medicamentos por via intramamária podem ter corroborado com a alta taxa de cura do grupo tratado.

O tratamento durante a lactação também pode ser prejudicado pela resistência antibiótica ou o desenvolvimento de resistência; pelo fenômeno de "dormência" bacteriana, quando antimicrobianos bactericidas não atuam sobre bactérias que não se multiplicam; por "L-forms" de bactérias, em que estas são deficientes em parede celular e, dessa maneira, não sensíveis a beta lactâmicos; pelo encapsulamento bacteriano; e por casos de reinfecção. Além disso, as propriedades farmacocinéticas do antimicrobiano podem interferir na capacidade de penetração da droga nos tecidos e na distribuição desta entre sangue e leite (BRITO et al., 2001).

Tabela 1 - Taxas de cura espontânea (sem tratamento com gentamicina) e não espontânea (tratamento com gentamicina) da mastite subclínica por Staphylococcus aureus durante a lactação.

\begin{tabular}{lccccc}
\hline & \multicolumn{5}{c}{ Evolução da mastite subclínica } \\
\cline { 2 - 7 } Condição & $\mathrm{n}$ & Quartos curados & $\%$ & Quartos não curados & $\%$ \\
\hline Sem tratamento & 68 & 5 & $7,4^{\mathrm{a}}$ & 63 & $92,6^{\mathrm{a}}$ \\
Com tratamento & 67 & 55 & $82,1^{\mathrm{a}}$ & 12 & $17,9^{\mathrm{a}}$ \\
\hline Total & 135 & 60 & 44,4 & 75 & 55,6 \\
\hline
\end{tabular}

${ }^{\mathrm{a}} \mathrm{P}<0,0001$ 
A glândula mamária é protegida por mecanismos de defesa primários e secundários que previnem a entrada de patógenos para o interior da glândula e combatem os micro-organismos pela liberação de mediadores derivados do plasma ou das células que podem ser importantes para a sobrevivência ou não de microrganismos como o $S$. aureus e influenciar na recuperação espontânea de quartos mamários com mastite subclínica (GUIDRY, 1985;SORDILLOet al.,1997).

A CCS e a produção de leite estão apresentadas na Tabela 2. Os valores encontrados para a CCS após o tratamento mostraram-se significativamente inferiores quando comparados com os valores de CCS anterior ao tratamento. ACCS média diminuiu de $461 \times 10^{3}$ células/ $\mathrm{mL}$ para $105 \times 10^{3}$ células/ $\mathrm{mL}$ após o tratamento, enquanto os valores médios para os quartos quenão foram tratados elevou-se de $425 \times 10^{3}$ células / $\mathrm{mL}$ para $531 \times 10^{3}$ células $/ \mathrm{mL}$. Houve diminuição da quantidade de leite produzida por quartos tratadose não tratados. Dessa maneira, a elevada taxa de cura encontrada após o tratamento antimicrobiano durante a lactação foi suficiente para influenciar a CCS, porém, efeitos positivos semelhantes não foram encontrados para a produção de leite.

Tabela 2 - Contagem de células somáticas (CCS) e produção média de leite em quartos mamários tratados e não tratados durante a lactação contra a mastite subclínica causada por Staphylococcus aureus, no intervalo de um mês.

\begin{tabular}{|c|c|c|c|c|}
\hline \multirow[b]{2}{*}{$\begin{array}{l}\text { Colheitas } \\
\text { de leite }\end{array}$} & \multicolumn{2}{|c|}{$\mathrm{CCS}\left(\times 10^{3} / \mathrm{mL}\right)^{1}$} & \multicolumn{2}{|c|}{ Produção (g) } \\
\hline & $\begin{array}{l}\text { Quartos } \\
\text { tratados }\end{array}$ & $\begin{array}{l}\text { Quartos } \\
\text { não } \\
\text { tratados }\end{array}$ & $\begin{array}{l}\text { Quartos } \\
\text { tratados }\end{array}$ & $\begin{array}{c}\text { Quartos } \\
\text { não } \\
\text { tratados }\end{array}$ \\
\hline Dia zero & $461^{\mathrm{a}}$ & 425 & 4.002 & 3.583 \\
\hline Dia 30 & $105^{\mathrm{a}}$ & 531 & 3.800 & 3.458 \\
\hline
\end{tabular}

${ }^{1}$ CCS: médias geométricas.

${ }^{\mathrm{a}} \mathrm{P}<0,0001$

Segundo Reis et al. (2003), duas semanas após a aplicação do cefacetril sódico houve diminuição da CCS no grupo tratado em comparação com a situação anterior ao tratamento, verificando-se elevação do número de células 25 e 40 dias após o tratamento, justificada pela ocorrência de recidivas das infecções tratadas em alguns animais, principalmente após 25 dias do tratamento.

A avaliação do tratamento foi efetuada 30 dias após a infusão antimicrobiana, desconhecendo-se os efeitos da terapia após este período. Ao mesmo tempo, desconhecem-se os efeitos do tratamento sobre a produção de leite em um período superior aos 30 dias mencionados. Sugere-se que mais trabalhos relacionados ao tema sejam feitos para a avaliação dos efeitos do tratamento em um período superior a estes 30 dias. A adoção de medidas preventivas para o controle da mastite provavelmente ajudariam na manutenção de animais livres de reinfecções e, consequentemente, colaborariam com CCSs reduzidas após o tratamento.

Os valores de EST e dos teores protéicos encontram-se na Tabela 3. Enquanto nos quartos mamários tratados os valores de EST foram de $11,1 \%$ e $11,8 \%$ antes e após o tratamento, respectivamente, para os quartos não tratados, em duas colheitas de amostras efetuadas em um intervalo de 30 dias, estes valores foram $11,3 \%$ e $11,0 \%$. Nos quartos mamários tratados, os valores médios das frações protéicas antes e após o tratamento foram de, respectivamente, $2,88 \%$ e 2,80\% para PT; $2,69 \%$ e 2,25\% para PV; $2,11 \%$ e $1,66 \%$ para CAS; e $0,58 \%$ e $0,58 \%$ para SP. Nos quartos mamários não tratados, no intervalo de 30 dias, os valores encontrados foram de $3,21 \%$ e $3,15 \%$ para PT; $3,03 \%$ e $2,94 \%$ para PV; $2,32 \%$ e $2,29 \%$ para CAS; e $0,78 \%$ e $0,59 \%$ para SP.

A concentração de sólidos totais pode mostrar uma tendência de redução com a elevação do número de células somáticas no leite, conduzindo a uma possível diminuição de rendimento industrial em laticínios e redução da qualidade do produto final. Entretanto, PRADA E Silva et al. (2000) concluíram não haver relação entre o aumento na contagem de células somáticas e a concentração de sólidos totais.

No presente trabalho, notou-se uma redução nos teores de PT, PV e CAS nos quartos tratados e não tratados, enquanto os teores de SP foram iguais nos quartossubmetidos ao tratamentocomantimicrobiano e reduziram-se nos quartos não tratados (Tabela 3 ). $\mathrm{O}$ leite de quartos mamários com mastite subclínica podem apresentar uma elevação nos níveis de soroproteínas devido ao aporte das proteínas do soro sanguíneo para o leite dos quartos doentes pelo aumento da permeabilidade capilar e consequente passagem destas proteínas para os alvéolos. Na mastite subclínica, assim, ocorre um aumento do conteúdo de proteína total do leite pelo aumento da lactoferrina, de imunoglobulinas e da soroalbumina bovina, proteínas associadas com respostas inflamatórias da glândula mamária (URECH et al., 1999).

Apesar da redução dos valores das frações protéicas (exceto SP), a elevação do EST após o tratamento com antimicrobiano pode ter ocorrido pela elevação de outros constituintes do leite, como a gordura e a lactose. As reduções nas frações protéicas, entretanto, foram acompanhadas pela redução do EST quando o tratamento não foi realizado. 
Tabela 3 - Valores médios de extrato seco total (\%) e das frações protéicas (\%) de amostras de leite de quartos mamários tratados e não tratados contra a mastite subclínica por Staphylococcus aureus, no intervalo de um mês.

\begin{tabular}{lcccccccc}
\hline & \multicolumn{3}{c}{ Quartos tratados } & & \multicolumn{3}{c}{ Quartos não tratados } \\
\cline { 2 - 4 } Características & Dia zero & Dia 30 & Variação (\%) & & Dia zero & Dia 30 & Variação (\%) \\
\hline EST $^{1}$ & 11,13 & 11,77 & 5,75 & & 11,26 & 11,03 & $-2,04$ \\
Proteína total & 2,88 & 2,80 & $-2,78$ & & 3,21 & 3,15 & $-1,87$ \\
Proteína verdadeira & 2,69 & 2,25 & $-16,36$ & & 3,03 & 2,94 & $-2,97$ \\
Caseínas & 2,11 & 1,66 & $-21,33$ & & 2,32 & 2,29 & $-1,29$ \\
Soroproteínas & 0,58 & 0,58 & 0,00 & & 0,78 & 0,59 & $-24,36$ \\
\hline
\end{tabular}

${ }^{1}$ EST: extrato seco total.

Segundo BuENo et al. (2005), o teor médio de proteína total reduziu de $3,35 \%$ para $3,18 \%$ à medida que a CCS aumentou (CCS inferior ou igual a 200.000 células/mL e CCS superior a 751.000 células/mL, respectivamente). Estes autores argumentaram, entretanto, que apenas $5,29 \%$ das variações no teor protéico poderiam ser atribuídas ao escore de células somáticas. NiELSENet al. (2005), por outro lado, relataram que o conteúdo de proteína do leite após a ordenha completa dos animais foi superior $(\mathrm{P}<0,01) \mathrm{em}$ quartos doentes $(3,49 \pm 0,14)$ quando comparados com quartos mamários sadios. Não foi descartada por estes autores a possibilidade de um menor efeito de diluição ter influenciado nos resultados encontrados.

Este menor efeito de diluição acontece, segundo MARTins et al. (2007), quando há a diminuição no volume de produção de leite e o consequente aumento da concentração dos seus componentes químicos. Estes autores encontraram elevados porcentuais de amostras de leite fora dos padrões para as concentrações de proteína, segundo a Instrução Normativa 51, o que indica a existência de diferenças regionais importantes e, talvez, a necessidade de melhorar-se o manejo nutricional e sanitário dos rebanhos em todos os sistemas de produção.

A caseína corresponde a, aproximadamente, $80 \%$ das proteínas do leite, sintetizadas inteiramente no interior da glândula mamária e consideradas financeiramente entre as mais importantes devido à sua relação com a produção de queijos (MACKLE et al., 1999). Segundo MARTins et al. (2006), em estudo efetuado na região dePelotas, Estado do RioGrande doSul, em meses de menor incidência de mastite ocorreram menores valores médios para os teores de caseína do leite, enquanto o inverso foi notado. Para estes autores, os maiores valores decaseína ocorridos nos meses de primavera e início do verão coincidiram com a melhoria das condições climáticas e maior oferta e qualidade das pastagens, apesar de MACKLE et al. (1999) relatarem que não houve efeitos da dieta dos animais sobre os teores de caseína do leite.
A influência da alimentação também foi a justificativa deGonZALEzet al.(2004) para a elevação do teor de proteína verdadeira no leite de animais pertencentes à bacia leiteira de Pelotas, no Rio Grande do Sul, nos meses de outubro enovembro, quando houveuma melhor oferta de forragem na primavera. Segundo estes autores, a substituição de silagem de milho por pastagem de boa qualidade pode levar a um aumento na produção de proteína pela maior digestibilidade da dieta e maior suporte de nutrientes, o que mostra a necessidade de integração dos vários segmentos responsáveis por uma boa produção animal no fornecimento de leite com índices protéicos adequados.

Encontrou-se, neste trabalho, reduzidos teores de protéina quando comparados com outros trabalhos. Segundo BAILEy etal.(1998), o conteúdo de proteína no leite pode diminuir em rebanhos que se apresentam suplementados com determinados alimentos. Além disso, os animais eram ordenhados uma vez ao dia, o que também pode diminuir os valores de proteína pelos efeitos de menor diluição citados por NIELSENet al. (2005) e MARTins et al. (2007). Animais próximos do final da lactação com uma menor produção de leite podem apresentar maiores teores protéicos no leite, $\mathrm{o}$ que pode ter influenciado nos valores mais elevados em animais que não foram tratados contra a mastite subclínica.

De acordo com os resultados apresentados, o tratamento da mastite subclínica causada pelo S. aureus durante a lactação não resultou em elevação dos teores protéicos após a terapia. SegundoBLOCK (2000), existe interesse por parte de alguns laticínios em analisar e pagar o produto pela fração de proteína verdadeira, devido a importância da porcentagem desta no leite usado no processamento. Talvez a elevação de determinadas frações protéicas do leite seja mais relevante com mudanças na alimentação dos animais e melhoria da qualidade de pastagens.

O uso de substâncias antimicrobianas na glândula mamária e os riscos que os seus resíduos podem representar à saúde da população devem conduzir à uma utilização consciente de medicamentos por par- 
te de técnicos e produtores. A utilização de antibióticos e quimioterápicos para o tratamento da mastite pode, dessa maneira, reduzir a qualidade do leite, mesmo quando a intenção é a melhoria do produto.

\section{CONCLUSÕES}

As análises dos dados permitiram concluir que não houve diferença significativa após os testes estatísticos para PT, PV eSP, enquanto a mesma diferença encontrada em quartos mamários doentes para CAS, antes e após o tratamento, também foi verificada para os quartos sadios que serviram de controle. Dessa maneira, conclui-se que o tratamento da mastite subclínica causada por $S$. aureus durante a lactação não acarretou melhoria na qualidade do produto quando os itens analisados foram os teores protéicos do leite, ao menos em rebanho com baixa produção e com uma ordenha diária, como o estudado.

\section{AGRADECIMENTOS}

Fundação de Amparo à Pesquisa do Estado deSão Paulo (Fapesp) - Processo No 98/16087-6.

\section{REFERÊNCIAS}

BAILEY, T.L.; WHITTIER, W.D.; MURPHY, J.; CURRIN, J.F. Using records to evaluate milk production. Veterinary Medicine, v.93, n.12, p.1083-1093, 1998.

BLOCK, E. Nutrição de vacas leiteiras e composição do leite. In: SIMPÓSIO INTERNACIONAL SOBRE QUALIDADE DO LEITE, 2., 2000, Curitiba. Anais. Curitiba: 2000. p.85-88.

BRITO, M.A.V.P.; BRITO, J.R.F.; SILVA, M.A.S.; CARMO, R.A. Concentração mínima inibitória de dez antimicrobianos para amostras de Staphylococcus aureus isoladas de infecção intramamária bovina. Arquivo Brasileiro de Medicina Veterinária e Zootecnia, v.53, n.5, p.531-537, 2001.

BUENO, V.F.F.; MESQUITA, A.J.; NICOLAU, E.S.; OLIVEIRA, A.N.; OLIVEIRA, J.P.; NEVES, R.B.S.; MANSUR, J.R.G.; THOMAZ, L.W. Contagem celular somática: relação com a composição centesimal do leite e período do ano no Estado de Goiás. Ciência Rural, v.35, n.4, p.848-854, 2005.

COSTA, E.O.; WATANABE, E.T.; SILVA, J.A.B.; GARINO JÚNIOR, F.; RIBEIRO, A.R. Tratamento da mastite clínica e subclínica por via intramamária: avaliação "in vitro" e "in vivo". In: CONGRESSO BRASILEIRO DE MEDICINA VETERINÁRIA, 25., 1997, Porto Alegre. Anais. Porto Alegre: 1997. p.278.
DELUYKER, H.A.; VAN OYE, S.N.; BOUCHER, J.G. Factors affecting cure and somatic cell count after pirlimycin treatment of subclinical mastitis in lactating cows. Journal of Dairy Science, v.88, n.2, p.604614, 2005.

FERREIRA, L.M.; NADER FILHO, A.; OLIVEIRA, E.; ZAFALON, L.F.; SOUZA, V. Variabilidade fenotípica e genotípica de estirpes de Staphylococcus aureus isoladas em casos de mastite subclínica bovina. Ciência Rural, v.36, n.4, p.1228-1234, 2006

FONSECA, L.F.L. Pagamento por qualidade: situação atual e perspectivas para o setor lácteo brasileiro parte 01. 2001. Disponível em: <http:/ / www. milkpoint.com.br>. Acesso em: 8 nov. 2001.

FONSECA, L.F.L.; SANTOS, M.V. Qualidade do leite e controle da mastite. São Paulo: Lemos Editorial, 2000. $175 \mathrm{p}$.

GONZALEZ, H.L.; FISCHER, V.; RIBEIRO, M.E.R.; GOMES, J.F.; STUMPF JÚNIOR, W.; SILVA, M.A. Avaliação da qualidade do leite na bacia leiteira de Pelotas, RS. Efeito dos meses do ano. Revista Brasileira de Zootecnia, v.33, n.6, p.1531-1543, 2004.

GUIDRY, A.J. Mastitis and the immune system of the mammary gland. In: ANDERSON, R.R. (Ed.). Lactation. Ames: Iowa State University Press, 1985. p.229-258.

HARMON, R.J.; EBERHART, R.J.; JASPER, D.E.; LANGLOIS, B.E.; WILSON, R.A. Microbiological procedures for the diagnosis of bovine udder infection. Arlington: National Mastitis Council, 1990. 34p.

HOLMBERG, O. Staphylococcus epidermidis isolated from bovine milk. Acta Veterinaria Scandinavica, v.45, p.1-144, 1973. Supplement.

HOLT, J.G.; KRIEG, N.R.; SNEATH, P.H.A.; STALEY, J.T.; WILLIAMS, S.T. Bergey's manual of determinative bacteriology. Baltimore: Williams \& Wilkins, 1994. p.544-551.

\section{INTERNATIONAL DAIRY FEDERATION.}

Determination of the total nitrogen content of milk by the Kjeldahl method. International Standard, 1962. (FIL-IDF 20).

INTERNATIONAL DAIRY FEDERATION. Standards 148. Milk. Enumeration of somatic cells. Brussels: IDF, 1991.

LANGONI, H.; DEVELEY, A.; DOMINGUES, P.F.; BALDINI, S.; SILVA, A.V.; SAVOLDI, F.; GEORGETTI, F.; LISTONI, F.J.P. Eficácia do Leocillin ${ }^{\mathrm{R}}$ no tratamento da mastite bovina. In: CONGRESSO BRASILEIRO DE MEDICINA VETERINÁRIA, 25., 1997, Porto Alegre. Anais. Porto Alegre: 1997. p.285. 
MACKLE, T.R.; BRYANT, A.M.; PETCH, S.F.; HOOPER, R.J.; AULDIST, M.J. Variation in the composition of milk protein from pasture-fed dairy cows in late lactation and the effect of grain and silage supplementation. New Zealand Journal of Agricultural Research, v.42, p.147-154, 1999.

MARTINS, P.R.G.; SILVA, C.A.; FISCHER, V.; RIBEIRO, M.E.D.; STUMPF JÚNIOR, W.; ZANELLA, M.B. Produção e qualidade do leite na bacia leiteira de Pelotas-RS em diferentes meses do ano. Ciência Rural, v.36, n.1, p.209-214, 2006.

MARTINS, P.R.G.; FISCHER, V.; RIBEIRO, M.E.D.; GOMES, J.F.; STUMPF JÚNIOR, W.; ZANELLA, M.B. Produção e qualidade do leite em sistemas de produção da região leiteira de Pelotas, RS, Brasil. Ciência Rural, v.37, n.1, p.212-217, 2007.

NIELSEN, N.I.; LARSEN, T.; BJERRING, M.; INGVARTSEN, K.L. Quarter health, milking interval, and sampling time during milking affect the concentration of milk constituents. Journal of Dairy Science, v.88, n.9, p.3186-3200, 2005.

OLIVER, S.P.; GILLESPIE, B.E.; HEADRICK, S.J.; MOOREHEAD, H.; LUNN, P.; DOWLEN, H.H.; JOHNSON, D.L.; CHESTER, S.T.; MOSELEY, W.M. Efficacy of extended ceftiofur intramammary therapy for treatment of subclinical mastitis in lactating dairy cows. Journal of Dairy Science, v.87, n.8, p.2393-2400, 2004.

PRADA E SILVA, L.F.; PEREIRA, A.R.; MACHADO, P.F.; SARRIÉS, G.A. Efeito do nível de células somáticas sobre os constituintes do leite II - lactose e sólidos totais. Brazilian Journal of Veterinary Research and Animal Science, v.37, n.4, 2000. Disponível em: <http://www.scielo.br/ scielo.php?script=sci_arttext\&pid=S141395962000000400 014\&lng=pt\&nrm=iso>.Acesso em: 15 mai 2007.
REIS, S.R.; SILVA, N.; BRESCIA, M.V.

Antibioticoterapia para controle da mastite subclínica de vacas em lactação. Arquivo Brasileiro de Medicina Veterinária e Zootecnia, v.55, n.6, p.651-658, 2003.

SAMPAIO, I.B.M. Estatística aplicada à experimentação animal. Belo Horizonte: Fundação de Ensino e Pesquisa em Medicina Veterinária e Zootecnia, 1998. 221p.

SHEPHARD, R.W.; MALMO, J.; PFEIFFER, D.U. A clinical trial to evaluate the effectiveness of antibiotic treatment of lactating cows with high somatic cell counts in their milk. Australian Veterinary Journal, v.78, n.11, p.763-768, 2000.

SORDILLO, L.M.; SHAFER-WEAVER, K.; DeROSA, D. Immunobiology of the mammary gland. Journal of Dairy Science, v.80, n.8, p.1851-1865, 1997.

URECH, E.; PUHAN, Z.; SCHALLIBAUM, M. Changes in milk protein fraction as affected by subclinical mastitis. Journal of Dairy Science, v.82, n.11, p.2402-2411, 1999. ZAFALON, L.F. Mastite subclínica bovina por Staphylococcus aureus: qualidade e quantidade de leite secretado por quartos tratados e não tratados e relação custo/benefício do tratamento durante a lactação. 2003. 66p. Tese (Doutorado) - Faculdade de Ciências Agrárias e Veterinárias, Universidade Estadual Paulista, Jaboticabal, 2003.

ZAFALON, L.F.; NADER FILHO, A.; AMARAL, L.A.; OLIVEIRA, J.V.; RESENDE, F.D. Produção e características físico-químicas e celulares do leite oriundo de quartos mamários de vacas com e sem mastite subclínica em três diferentes fases de lactação. Boletim de Indústria Animal, v.62, n2, p.117-124, 2005.

Recebido em 18/5/07

Aceito em 5/2/09 